\title{
A NOVA LEGISLAÇÃO PORTUÁRIA BRASILEIRA E A RESPONSABILIDADE GIVIL DO OPERADOR PORTUÁRIO: A JURISPRUDÊNGIA ESTADUAL DO PARANÁ
}

\author{
Frederico E. Z. GLITZ*
}

SumáRIO: I. Introdução. II. Análise dos casos encontrados. III. Notas conclusivas. IV. Bibliografia.

\section{INTRODUÇÃO}

O marco normativo da atividade portuária no Brasil foi alterado pela Lei $\mathrm{n}^{\circ} 12.815 / 2013$ que se propôs a regular a exploração dos portos, instalações portuárias e demais atividades desempenhadas pelos operadores portuários.

Para fazê-lo, conceituou o operador portuário como aquela "pessoa jurídica pré-qualificada para exercer as atividades de movimentação de passageiros ou movimentação e armazenagem de mercadorias, destinadas ou provenientes de transporte aquaviário, dentro da área do porto organizado" (artigo 2o., XIII).

Como se percebe do próprio conceito normativo, a atividade destinada ao operador portuário é bastante extensa. Se, ainda, considerarmos que sua atividade se inicia com a entrada da mercadoria "em seus armazéns, pátios ou locais outros designados para depósito" e só se encerra com a entrega efetiva no navio, por exemplo (artigo 2o. do Decreto-lei ${ }^{\circ}$ 116/1967), daí sim se pode dizer que se está diante de um dos mais férteis espaços para exemplos de responsabilidade civil.

Apesar disso, os Tribunais brasileiros não têm sido chamados a resolver significativo número de casos sobre tal tema. Algumas explicações parecem plausíveis: existem mecanismos contratuais que podem "incentivar"

* Advogado; doutor em Privado pela Universidade Federal do Paraná (2011); professor do Programa de Mestrado em Direito da Universidade Comunitária da Região de Chapecó (UNOCHAPECÓ) e da Pós-graduação em Direito do Centro Universitário de Curitiba (UNICURITIBA) (Frederico@fredericoglitz.adv.br). 
o deslocamento da discussão para o eixo contratual estabelecido entre as partes (incoterms ${ }^{1}$ e outras cláusulas de transferência de riscos seriam bons exemplos) e, além disso, no Brasil, o operador de transporte multimodal assume responsabilidade verdadeiramente ampla (a teor dos artigos $12 \mathrm{e}$ 13 da Lei nº 9.611/1998), ainda que mantenha ação regressiva (artigo 12, parágrafo único).

Ainda assim, a entrada em vigor da Lei ${ }^{\circ} 12.815 / 2013$ manteve a menção específica da responsabilização do operador portuário, ainda que tal responsabilidade pudesse ser deduzida da legislação geral, mas o faz de forma a não deixar claro em que termos esta responsabilização se dá. ${ }^{2}$

O presente trabalho, então, se propõe a investigar, com base na Jurisprudência passada, qual seria a provável orientação interpretativa para responsabilizar o operador portuário para os danos que este viesse a causar a terceiros, em sendo estes puramente particulares.

Para responder a este questionamento, buscou-se delimitar a pesqui$\mathrm{sa}^{3}$ a apenas dois Tribunais: o Tribunal de Justiça do Estado do Paraná, justamente em razão do seu porto, Paranaguá; e ao Superior Tribunal de Justiça, uma vez que tem por função a uniformização da matéria. Para alcançar o objetivo não se limitou a busca em termos temporais, e se tratou

1 Glitz, Frederico Eduardo Zenedin, "Transferência do risco contratual e incoterms: breve análise de sua aplicação pela jurisprudência brasileira”, Revista do Instituto do Direito Brasileiro, vol. 5, 2013, pp. 3885-3944.

2 Artigo 26. O operador portuário responderá perante:

I. A administração do porto pelos danos culposamente causados à infraestrutura, às instalações e ao equipamento de que a administração do porto seja titular, que se encontre a seu serviço ou sob sua guarda;

II. O proprietário ou consignatário da mercadoria pelas perdas e danos que ocorrerem durante as operações que realizar ou em decorrência delas;

III. O armador pelas avarias ocorridas na embarcação ou na mercadoria dada a transporte;

IV. O trabalhador portuário pela remuneração dos serviços prestados e respectivos encargos;

V. O órgão local de gestão de mão de obra do trabalho avulso pelas contribuições não recolhidas;

VI. Os órgãos competentes pelo recolhimento dos tributos incidentes sobre o trabalho portuário avulso; e

VII. A autoridade aduaneira pelas mercadorias sujeitas a controle aduaneiro, no período em que lhe estejam confiadas ou quando tenha controle ou uso exclusivo de área onde se encontrem depositadas ou devam transitar.

3 A pesquisa foi realizada em 25 de agosto de 2014. 
de realizar, no Superior Tribunal de Justiça, a pesquisa com três diferentes combinações de verbetes: "operador portuario" (resultando 58 resultados); "operador portuario" e "responsabilidade civil" (resultando 0 resultados) e "operador portuario" e "responsabilidade" (resultando 8 resultados).

Os verbetes de forma proposital omitiram qualquer acentuação. Desta última combinação, foram encontrados: três casos de natureza puramente tributária; três casos de natureza puramente administrativa e apenas dois casos em que o Superior Tribunal de Justiça afirma estar diante de matéria de responsabilidade civil, mas que acaba deixando de analisar qualquer aspecto essencial (e esclarecedor) de sua fundamentação, uma vez que isso importaria reexame fático, proibido pela Súmula $n^{\circ} 7$ da mesma Corte.

Aparentemente, portanto, o Superior Tribunal de Justiça não poderia fornecer a resposta buscada.

No Tribunal de Justiça do Paraná, a pesquisa se realizou com apenas uma combinação de verbetes: "operador portuario" (também se omitindo acentuação), mas se acrescentou um requisito: os verbetes deveriam aparecer na ementa do acórdão. Foram localizados 11 (onze) casos, sendo dois deles exclusivamente de matéria trabalhista (acidente e segurança do trabalho) e outro se referia a declaração do operador portuário para fins de prescrição. Serão, portanto, os 8 (oito) restantes julgados, que servirão de fio condutor do presente artigo.

Advirta-se, ainda, que a pesquisa se baseia quase que exclusivamente na análise jurisprudencial por dois motivos: (i) de ordem prática, buscase entender como o intérprete "autêntico" encara a principal atividade logística do comércio internacional e, talvez, seu principal "nó", ${ }^{4}$ e (ii) a pesquisa doutrinária revela escassos recursos não só sobre o tema portuário em si, mas igualmente sobre a temática da responsabilidade civil do operador portuário.

Ainda que a matéria seja extremamente relevante, em busca de uma resposta minimamente satisfatória, resta-nos explorar a fonte, ainda que também escassa, da jurisprudência estadual. Eis a senda se que passa a trilhar.

4 Outro "nó" que pode ser mencionado é a infraestrutura portuária e os consequentes custos de atraso no embarque/desembarque da mercadoria. Para maiores detalhes, vide Glitz, Frederico Eduardo Zenedin, "Mora na devolução do contêiner: análise da visão jurisprudencial brasileira acerca do comércio internacional", Revista do Instituto de Direito Brasileiro, núm. 11, 2013, pp. 12423-12463. 


\section{ANÁlise dOS CASOS ENCONTRADOS}

Antes da vigência da atual legislação, vigorava a Lei nº 8.630/1993 cujo artigo $11^{5}$ tinha redação muito similar aquela do atual artigo 26 da Lei $n^{\circ}$ 12.815/2013.

Pode, portanto, ser muito útil compreender como foram entendidos os casos julgados e fundamentados a partir da Lei ${ }^{\circ}$ 8.630/1993 de modo a se concluir qual seria a tendência de interpretação da atual legislação.

Advirta-se, contudo, que este é um exercício argumentativo, na medida em que 20 (vinte) anos separam as duas legislações. Não só teses doutrinárias se desenvolveram como tendências jurisprudenciais se consolidaram. A semelhança da redação, contudo, pode indicar elementos de interpretação e, mesmo, afastar algumas dúvidas dos atuais intérpretes.

Destaque-se, por fim, que todos os oito casos localizados na jurisprudência do Tribunal paranaense, seguindo os critérios delineados na introdução deste artigo, foram jugados sob a égide da legislação revogada. Passemos a entendê-los:

2.1 O primeiro caso ${ }^{6}$ é recurso em que se discutiu a responsabilidade da Administração dos Portos de Paranaguá e Antonina (APPA) em razão

5 Artigo 11. O operador portuário responde perante:

I. A Administração do Porto, pelos danos culposamente causados à infra-estrutura, às instalações e ao equipamento de que a mesma seja a titular ou que, sendo de propriedade de terceiro, se encontre a seu serviço ou sob sua guarda;

II. O proprietário ou consignatário da mercadoria, pelas perdas e danos que ocorrerem durante as operações que realizar ou em decorrência delas;

III. O armador, pelas avarias provocadas na embarcação ou na mercadoria dada a transporte;

IV. O trabalhador portuário, pela remuneração dos serviços prestados e respectivos encargos;

V. O órgão local de gestão de mão-de-obra do trabalho avulso, pelas contribuições não recolhidas;

VI. Os órgãos competentes, pelo recolhimento dos tributos incidentes sobre o trabalho portuário avulso.

6 Paraná, Tribunal de Alçada. Ação de ressarcimento. Indenização promovida pela seguradora contra a Administradora do Porto de Paranaguá - APPA - (art. 1521, III, CG). Culpa do preposto não comprovada. Improcedência. Retirada de container do navio Responsabilidade do operador portuário (L. 8630/93). Recurso improvido. Companhia Paulista de Seguros versus Administração dos Portos de Paranaguá e Antonina - APPAApelação Cível no 179.195-3. $7^{\mathrm{a}}$ Câmara Cível. Relator Juiz Miguel Pessoa. Julgado em 16 de abril de 2003. 
Esta revista forma parte del acervo de la Biblioteca Jurídica Virtual del Instituto de Investigaciones Jurídicas de la UNAM

da queda do container (quando de sua movimentação) e consequente avaria. A seguradora, sub-rogada no crédito pretendia responsabilizar a APPA uma vez que seria seu dever realizar as operações portuárias (entre elas a operação do maquinário necessário — no caso portainer -).

O Tribunal, contudo, entendeu que a Administração do porto "não possui responsabilidade pela retirada ou pelo carregamento de navios, tão somente o depósito e armazenagem das mercadorias e containers após serem estes descarregados" e que tal descarga se daria por "empresas privadas" contratadas pelo comandante do navio e dono da mercadoria. Destaca, por fim, a Câmara que o critério para tal responsabilização seria a culpa, ou seja, estar-se-ia diante de uma hipótese de responsabilidade subjetiva.

2.2 O segundo caso $^{7}$ envolvia a discussão sobre o ressarcimento por indenização paga poravarias causadas no casco do navio. $\mathrm{O}$ Tribunal paranaense, também utilizando o teor do artigo 11 da Lei no 8.630/1993, atribui tal responsabilidade ao "operador portuário". O detalhe do caso é que a responsabilidade do operador era reforçada por cláusula contratual expressa em que ele assumia, contratualmente, a responsabilidade pelas avarias ocasionadas ao navio e outros equipamentos. Neste caso o Tribunal não se refere a nenhum critério de responsabilização, além da cláusula contratual e do próprio dispositivo do artigo 11 da Lei n8.630/1993.

$2.3 \mathrm{O}$ terceiro caso $^{8}$ envolvia discussão sobre a avaria em carga de vidros acondicionada em contêineres sob a responsabilidade de determinado operador. Tais contêineres teriam sido retirados do navio e embar-

7 Paraná, Tribunal de Justiça. Apelação cível - Inaplicabilidade do artigo 557, §1 -'A' do Código de Processo Civil, quando verificada razões recursais passíveis de controvérsia Ação de resolução contratual c/c reparação de danos e compensação de dívidas - Preliminar de incompetência absoluta em razão de litispendência - Inocorrência - Cerceamento do direito de defesa ante o julgamento antecipado da lide - Inocorrência - Operador portuário contratado para efetuar a operação de embarque - Acidente quando do carregamento da mercadoria - Avaria no casco do navio - Lei 8630/93, art. 11 - Responsabilidade do operador portuário - Dívida paga pela apelada - Sub-rogação - Ocorrência - Ausência de notificação do devedor - Irrelevância - Compensação com o crédito oriundos da operação contratada - Possibilidade - Recurso adesivo - Interposição exteporânea - Não conhecimento. Recurso adesivo não conhecido. Recurso de apelação desprovido. Marcon Serviços de Despachos em Geral Ltda versus Gerdau Açominas S/A. Apelação Cível n 345315-4. $9^{\text {a }}$ Câmara Cível. Relator Des. José Aniceto. Julgado em 16 de outubro de 2008.

8 Paraná, Tribunal de Justiça. Apelação cível - Ação de indenização - Avarias em container - Transporte infra-porto - Ato ilícito não configurado por parte do operador portuário - Ausência do dever de indenizar - Manutenção da sentença. Recurso desprovido. 
cados em um caminhão, mas no percurso (dentro do porto) a mercadoria tombou e acabou se avariando. Com isso a discussão instaurada é se a responsabilidade seria ou não do operador portuário.

O Tribunal entendeu que como as avarias não ocorreram durante as atividades de carga e descarga, o operador não poderia ser responsabilizado. Neste caso, mais uma vez, o Tribunal paranaense exigiu, expressamente, a necessidade de demonstração do elemento "culpa" para responsabilização do operador portuário.

2.4 O quarto caso envolvia ${ }^{9}$ pretensão indenizatória de empresa que teve quantidade de mercadoria entregue (desembarque) a menor do que aquela embarcada. Neste caso, o acórdão considerou que o operador portuário exerceria "serviço público federal" (a teor do artigo lo. da Lei n8.630/1993) e, portanto, sua responsabilidade seria objetiva.

Esta é a primeira vez em que este entendimento aparece na jurisprudência do Tribunal paranaense. Alguns dados, no entanto, são ainda mais significativos: (i) o precedente citado como fundamento do julgado é o precedente objeto do item 2.2 acima, em que nenhum parâmetro de responsabilização foi mencionado e, mais, havia cláusula contratual expressa de responsabilização; (ii) a mesma Câmara do Tribunal paranaense até então julgava os mesmos casos baseados no artigo 11 da Lei $\mathrm{n}^{\circ} 8.630 / 1993$ como sendo de responsabilidade subjetiva.

2.5 No quinto caso ${ }^{10}$ discutiu-se a possibilidade de existência de responsabilidade solidária entre o transportador e o operador portuário por perda parcial da carga. O Tribunal, ao interpretar o dispositivo do artigo

Apelação Cível no 379168-0. Vidraçaria Linde Ltda versus Wilport Operadores Portuários

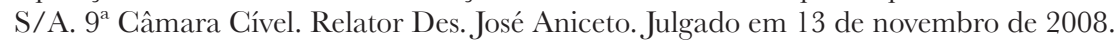

9 Paraná, Tribunal de Justiça. Apelação cível - Ação de ressarcimento - Preliminar de prescrição - Não configurada - Mérito - Desembarque de mercadoria no porto - Quantidade especificada no laudo da receita federal quando do atracamento do navio entregue em menor quantia ao destinatário - Documento público - Presunção iuris tantum - Responsabilidade objetiva do operador portuário - Concessionário de serviço público - Dever de indenizar. Recurso desprovido. Apelação Cível no 596147-9. Fortesolo Serviços Integrados Ltda versus Bradesco Seguros S/A. 9a Câmara Cível. Relator Des. José Aniceto. Julgado em 29 de outubro de 2009.

10 Paraná, Tribunal de Justiça. Seguro. Ação regressiva. Danos à carga transportada. Operadora portuária. Responsabilidade restrita aos danos causados a carga durante a operação de descarga. Ausência de responsabilidade solidária entre ela e o transportador pela simples constatação da perda parcial da carga. Apelação provida. Apelação Cível n ${ }^{\circ}$ 566.481-7. Rocha Top Terminais e Operadores Portuários Ltda versus Bradesco Seguros S. 
11 da Lei n8.630/1993, considerou que a responsabilidade do operador portuário estaria adstrita à operação de carga e descarga, não podendo ser estendida para eventuais danos ocorridos durante o transporte (daí porque não se poderia falar em solidariedade). Este mesmo entendimento já havia, de alguma forma, sido dado no caso descrito no item 2.3.

2.6 No sexto caso $^{11}$ as mesmas partes do caso anterior estavam envolvidas, mas desta vez, a matéria versava sobre pretensão de ressarcimento securitário em razão de a operadora portuária ter indenizado cliente que teve perdas no momento do embarque da mercadoria. Em primeiro grau, se concluiu que havia nexo de causalidade entre a atividade do operador e o suposto dano sofrido, motivo pelo qual não haveria o porquê de tal ressarcimento.

O acórdão enfatiza que o operador não só teria responsabilidade objetiva ("exercício de atividade pública") como, no caso, nãoteria conseguido demonstrar como os documentos oficiais que demonstrariam a perda da mercadoria estariam equivocados. Mais uma vez, portanto, o Tribunal retorna o fundamento (vide item 2.4) de que a responsabilidade do operador portuário seria objetiva, pois aquela da Administração.

2.7 O sétimo caso ${ }^{12}$ envolvia o pedido de reforma de decisão que condenou a operadora portuária a pagar, em regresso, a seguradora o valor

A. Décima Câmara Cível. Relator Juiz Convocado Albino Jacomel Guérios. Julgado em 14 de janeiro de 2010.

11 Paraná, Tribunal de Justiça. Apelação cível - Responsabilidade civil - Operador portuário - Seguradora que pretende o ressarcimento da indenização paga a sua segurada em virtude da perda de mercadoria pela requerida, operadora portuária - Legitimidade passiva configurada, vez que nos autos se discute justamente a conduta da requerida - Prazo trienal de prescrição, referente à ação por responsabilidade civil - Prazo anual do DL 116/67 que não se aplica à discussão entre operador portuário e importador - Desnecessidade de ingresso na lide da APPA, porquanto seja a responsabilidade da requerida o objeto da discussão - Descompasso entre a quantidade de mercadoria analisada pela receita federal e aquela que efetivamente chegou à importadora - Perda que se operou enquanto a mercadoria estava sob a responsabilidade da ré - Requerida que, mesmo respondendo objetivamente pelos danos causador, não logrou demonstrar eventuais excludentes de responsabilidade - Indenização devida - Apelo desprovido. Apelação Cível no 679795-3. Rocha Top Terminais e Operadores Portuários Ltda versus Bradesco Seguros S. A. Décima Câmara Cível. Relatora Juíza Convocada Denise Kruger Pereira. Julgado em 8 de julho de 2010.

12 Paraná, Tribunal de Justiça. Recurso de apelação. Ação regressiva de ressarcimento de seguro. Alegada nulidade da sentença por cerceamento de defesa. Ré que é intimada para especificar as provas e permanece inerte. Preclusão. Ausência de manifestação inclusive após a audiência para a qual restou intimada. Julgamento antecipado que não ofende 
da indenização que esta havia pago ao segurado em razão das perdas que este havia sofrido (desaparecimento de mercadoria no Armazém da operadora portuária). O Tribunal manteve a decisão sem, contudo, esclarecer se a responsabilidade da operadora seja objetiva ou subjetiva.

$2.8 \mathrm{O}$ oitavo, e último caso ${ }^{13}$ encontrado na jurisprudência paranaense, tratava-se de caso de ação indenizatória em que seguradora buscava o ressarcimento securitário em razão de indenização paga por perda parcial de mercadoria (carga declarada no porto de origem/carga desembarcada). O Tribunal considerou haver responsabilidade objetiva do operador (citando o caso relatado no item 2.4 como precedente).

Embora tenham sido poucos os casos julgados pelo Tribunal paranaense, algumas conclusões podem ser retiras. É o que faremos já em sede de encerramento deste texto.

\section{NOTAS GONGLUSIVAS}

O Tribunal paranaense embora tenha revelado apenas oito casos revelou uma tendência bastante interessante: a responsabilidade do operador portuário passa de subjetiva a objetiva. Aparentemente hoje este entendimento é consolidado naquele Tribunal.

Também parece estar consolidado o entendimento de que a responsabilidade do operador portuário, na jurisprudência paranaense, é objetiva com base na responsabilidade da Administração Pública. Este entendi-

a ampla defesa. Juiz que é o destinatário das provas. O operador portuário responde perante proprietário ou consignatário da mercadoria, pelas perdas e danos que ocorrerem durante as operações que realizar ou em decorrência delas. Inteligência do art. 11, II da Lei $n^{\circ}$ 8630/93. Sentença mantida. Recurso não provido. Apelação Cível n 887.733-2. Multitrans Transportes e Armazéns Gerais Ltda versus Royal \& Sunalliance Seguros (Brasil) S/A. Décima Câmara Cível. Relatora Juíza Convocada Denise Antunes. Julgamento em 16 de agosto de 2012.

13 Paraná, Tribunal de Justiça. Apelação cível - Ação de ressarcimento - Preliminar de prescrição não acolhida - Transporte marítimo de mercadoria - Desembarque de quantidade menor que a registrada no laudo da receita federal - Documento público - Presunção iuris tantum - Responsabilidade objetiva do transportador e do operador portuário Concessionário de serviço público - Dever de indenizar - Inocorrência de sucumbência recíproca - Honorários sucumbenciais mantidos - Valor adequado com o trabalho desenvolvido - Recursos desprovidos. Apelação Cível no 901.630-0. Cargill Internacional versus Fospar S/A e Itaú XL Seguros Corporativos S/A. 9a Câmara Cível. Relator Des. Renato Braga Bettega. Julgamento em 30 de agosto de 2012. 
mento, contudo, foi o fundamento de um único julgado, repetido a partir de então por mais um julgado (de forma expressa).

Então, embora se possa dizer que o Tribunal de Justiça do Paraná hoje julga a responsabilidade do operador portuário como sendo um caso de responsabilidade objetiva baseando na responsabilidade da Administração, tal justificativa é pouco fundamentada em qualquer dos acórdãos que a mencionam.

Por outro lado, a escassa doutrina acerca do tema prefere abordar a responsabilidade civil do operador portuário em termos de responsabilidade civil objetiva, mas o faz, normalmente, em razão da atividade empresarial que o operador exerce. ${ }^{14}$ Esta, aliás, parece ser a melhor opinião a respeito do tema.

Isso porque o operador portuário não exerce atividade própria da Administração, nem mesmo serviço público concedido ou delegado. ${ }^{15}$ Tratase, nitidamente, de atividade exercida por terceiro que, gerenciando os riscos a que a atividade está sujeita, trata de obter o lucro a que a toda a atividade empresarial está voltada. ${ }^{16}$

A explicação que a responsabilidade civil dá para os danos advindos do exercício de tal atividade ${ }^{17}$ é, justamente, o "risco", ou seja, a responsabilidade objetiva. A positivação de tal lógica encontra-se, hoje, respaldo no artigo 931 do Código Civil brasileiro.

Outros "indícios" poderiam ainda ser buscados: (i) a própria Lei ${ }^{\circ}$ 12.815/2013 quando quer se referir a alguma responsabilização específica, menciona o critério "culpa" (artigo 26, I, por exemplo) e (ii) tradicio-

14 Queiroga, Bernardo Henrique Campos, "A responsabilidade civil do operador portuário perante o proprietário da carga, pelas avarias desta e perante terceiros estranhos ao contrato de operação portuária", Revista de Direito Aduaneiro, Marítimo e Portuário, núm. 13, março-abril de 2013, pp. 51-64.

15 "Não bastasse isso, o próprio art. 21 do Decreto n 8033/2013 que regulamenta a Lei n 12.815/2013 prevê: «Os contratos celebrados entre a concessionária e terceiros serão regidos pelas normas de direito privado, não se estabelecendo qualquer relação jurídica entre os terceiros e o poder concedente, sem prejuízo das atividades regulatória e fiscalizatória da Antaq»".

16 Outro "indício" neste sentido é que o artigo 37 do Decreto n 8033/2013 quando prevê a indicação de representantes da "classe empresarial" no Conselho da autoridade portuária menciona os operadores portuários (artigo 37, II, b).

17 Noronha, Fernando, "Desenvolvimentos contemporâneos da responsabilidade civil”, Revista dos Tribunais, São Paulo, núm. 761, março de 1999, pp. 31-44. 
nalmente toda a atividade de transporte é regulada, por tradição legislativa e jurisprudencial, no Brasil, pela responsabilidade objetiva.

Ao lado da responsabilidade civil objetiva, embora por outro fundamento, a análise da jurisprudência do Tribunal paranaense revelou ainda dois outros dados: (i) em princípio a extensão da responsabilidade do operador portuário seria adstrita às operações de embarque e desembarque, mesmo que eventuais avarias acontecessem em transporte dentro do próprio porto; e (ii) não seria admitida a extensão de sua responsabilidade pela via da responsabilização solidária.

Em que pesem eventuais divergências quanto à fundamentação, a análise dos julgados do Tribunal de Justiça do Paraná revela como, diante de parcos recursos normativos e de quase inexistentes fontes doutrinárias, ainda assim os institutos do Direito Portuário alcançam algum tipo de solução judicial técnica.

\section{BIBLIOGRAFIA}

GLITZ, Frederico Eduardo Zenedin, "Mora na devolução do contêiner: análise da visão jurisprudencial brasileira acerca do comércio internacional", Revista do Instituto de Direito Brasileiro, núm. 11, 2013.

_- "Transferência do risco contratual e incoterms: breve análise de sua aplicação pela jurisprudência brasileira", Revista do Instituto do Direito Brasileiro, vol. 5, 2013.

Noronha, Fernando, "Desenvolvimentos contemporâneos da responsabilidade civil", Revista dos Tribunais, São Paulo, vol. 761, março de 1999. QueIRogA, Bernardo Henrique Campos, "A responsabilidade civil do operador portuário perante o proprietário da carga, pelas avarias desta e perante terceiros estranhos ao contrato de operação portuária", Revista de Direito Aduaneirro, Marítimo e Portuário, núm. 13, março-abril de 2013. 